\title{
Approach for Evaluating the Effectiveness of Rail Freight Transport in Reducing Logistics Costs and Carbon Dioxide $\left(\mathrm{CO}_{2}\right)$ Emissions
}

\author{
Guoquan LI, Dr. Eng. \\ Senior Researcher, \\ Transport Planning Laboratory, Transport Information Technology Division
}

\begin{abstract}
This paper investigates the reduction in logistics costs and carbon dioxide $\left(\mathrm{CO}_{2}\right)$ emissions which can be induced by shifting freight from road to rail, focusing on inter-regional surface freight convoys carrying manufactured goods. The article provides a summary analysis of the areas served by rail freight terminals, the relationships between, regions and a target rail corridor in the light of the rail freight sector's present situation in Japan. Using competitiveness criteria for rail freight based on expense analysis models, the distribution of shipped freight suitable for carriage by rail within the influential area of various terminals in each region is determined for the target corridor. Finally, with the help of a case study we determine the effectiveness of moving freight by rail in terms of reducing logistics costs and $\mathrm{CO}_{2}$ emissions on the target corridor.
\end{abstract}

Keywords: surface freight transport, modal shift, logistics costs and environmental load reduction, evaluation method

\section{Introduction}

Rail freight transport has generally been evaluated on the basis of operators' performance and business situations, namely, whether the operator runs a profit or deficit. Such approaches to evaluation are clearly necessary if operators' businesses are to be maintained as going concerns. However, it is increasingly important to consider other aspects when evaluating freight transport, such as logistics costs and environmental loads. While road haulage presently accounts for a large share of the surface freight transport market, the value of rail freight transport may be underestimated in view of these more all-encompassing evaluation criteria. Rail freight transport should be evaluated objectively by considering its current situation and whether it benefits the regional economy, and to what extent.

This paper aims to provide a balanced appraisal of rail freight transport by quantitatively estimating the railinduced reduction in logistics costs and environmental loads, represented by carbon dioxide $\left(\mathrm{CO}_{2}\right)$ emissions' levels, based on the transport records of the railway in question. The specific focus is on the benefits currently provided by rail freight transport, and the potential effects that may be achieved if freight is shifted from road to rail.

This study firstly analyzes the freight suitable for carriage by rail based on the records kept for inter-regional surface freight shipped by manufacturers. Secondly, a concept to evaluate the target railway corridor for freight transport is described, and a relevant procedure to estimate the social and economic effects of freight transport on the corridor established. We then investigate the influential area of each freight terminal and its current relationship with the target rail corridor according to transport records. We also examine the routing of surface freight within the influential area in order to sort and extract those convoys potentially passing along the target corridor. Further, we identify freight for which the "favorableness of logistics costs" criteria provided by the preceding study [1] indicated that shifting it to rail would be beneficial from the viewpoint of shippers' transport costs. Finally, using a case study for the target rail corridor, through comparative analyses of the freight transported along the corridor by rail and road, we quantitatively evaluate the current and potential economic effect of freight transport in terms of logistics costs' reductions and the social effect of $\mathrm{CO}_{2}$ emissions' reductions on the corridor.

This method for evaluating the reduction in logistics costs and environmental load is expected to be an efficient tool in understanding the value of rail freight in transport policy.

\section{Rail freight in inter-regional surface freight transport}

\subsection{Current freight transport situation}

According to the Regional Freight Flow Survey conducted by the Ministry of Land, Infrastructure, Transport and Tourism [2], the total volume of domestic freight decreased from 6.96 billion tons in the early 1990 s to 5.56 billion tons in 2007 . However, inter-regional freight flows grew from 1.62 billion tons to 1.86 billion tons during the same period.

A comparison between road haulage and rail freight in terms of their share of the surface freight transport market revealed that road accounts for an overwhelming proportion of short-distance transport, and that even over long distances of over 1,000 kilometers road haulage's share was still more than three times larger share than that of rail [3].

Essentially, railways have an advantage in longerdistance transport. It is necessary to determine which existing freight shipments are suitable for railway transport. 


\subsection{Surface freight transport potentially transportable by rail}

Whether or not surface freight suitable for transport by rail exists can be judged by a comparative analysis of road haulage and the current situation of rail freight transport. If both modes are similar, then the potential demand for rail freight induced by intermodal (road-rail) freight transport or modal shift from road to rail can be ascertained.

Japan is divided into nine regions; the current situation as regards inter-regional surface freight transport was analyzed nationwide using questionnaires to manufacturers, freight operators and forwarders, and National Commodity Flow Survey data [4].

First, the production and sales volumes of shipping manufacturers, freight volume per shipment, and shipping schedules in each region were compared between transport modes. The content and destination of the freight were then analyzed. The results indicated that shipment types in inter-regional freight transport are similar among rail, trucks and trailers. It means that these shipments are also suitable for carriage by rail. Therefore, freight currently transported by road can be considered as potential demand that may be shifted to rail. The majority of the items carried on such convoys, potentially new business for the railways, consist of machinery, chemical products, light industrial products and miscellaneous products, which account for $32 \%, 29 \%, 22 \%$ and $7 \%$, respectively. On the other hand, current rail freight volumes consist of $2.5 \%$ light industrial products, $2 \%$ chemical products and $1.5 \%$ machinery, indicating a significantly lower share compared to road haulage [5] and [6].

A considerable proportion of inter-regional surface freight could be shifted to rail. However, to do so it is necessary to devise a comprehensive logistics system, such as providing transport services that meet shippers' needs and building an intermodal transport system by coordinating the combination of different transport modes.

\section{Rail freight transport on major corridors and relevant evaluation procedure}

\subsection{Rail freight transport on major corridors}

The majority of rail freight is currently transported by container. The basic means of transporting freight is therefore first collecting freight by truck from shippers and transporting it to the departure terminal, then loading the convoy onto freight trains, running across a number of rail corridors, carrying the convoy to the arrival terminal, and finally delivering the goods to the recipient by truck, as shown in Fig.1. In reality, therefore, container transport by rail is a combination of on-rail transport and pick-up and delivery by truck.

When considering rail freight transport, the followings, at least, should all be considered: the condition of rail corridors in the network, collecting/delivering trucks, access conditions to and from freight terminals and the geographical distribution of shippers vis-à-vis terminals.

\subsection{Evaluation procedure of the social and economic effects of rail freight}

It is often said that rail transport is environmentallyfriendly, or less costly when moving shipments longer than a threshold distance. In this section, we have quantified such benefits. More concretely, the social and economic effect is estimated by quantifying the reduced costs and $\mathrm{CO}_{2}$ emissions achieved by carrying goods between fairly distant regions by rail instead of road. The formula used to estimate this effect is illustrated in Fig. 2.

For freight which could potentially be transported by rail on certain sections, the $\mathrm{CO}_{2}$ emissions of road transport and rail freight transport are compared, including on-rail transport and truck access for the collection and delivery of containers. The difference between the two can be considered as the social benefit. Naturally, the sign of the benefit should be positive.

Similarly, an economic benefit can also be determined by comparing the transport costs of trucks and trains on the corridor, including truck access for the collection and

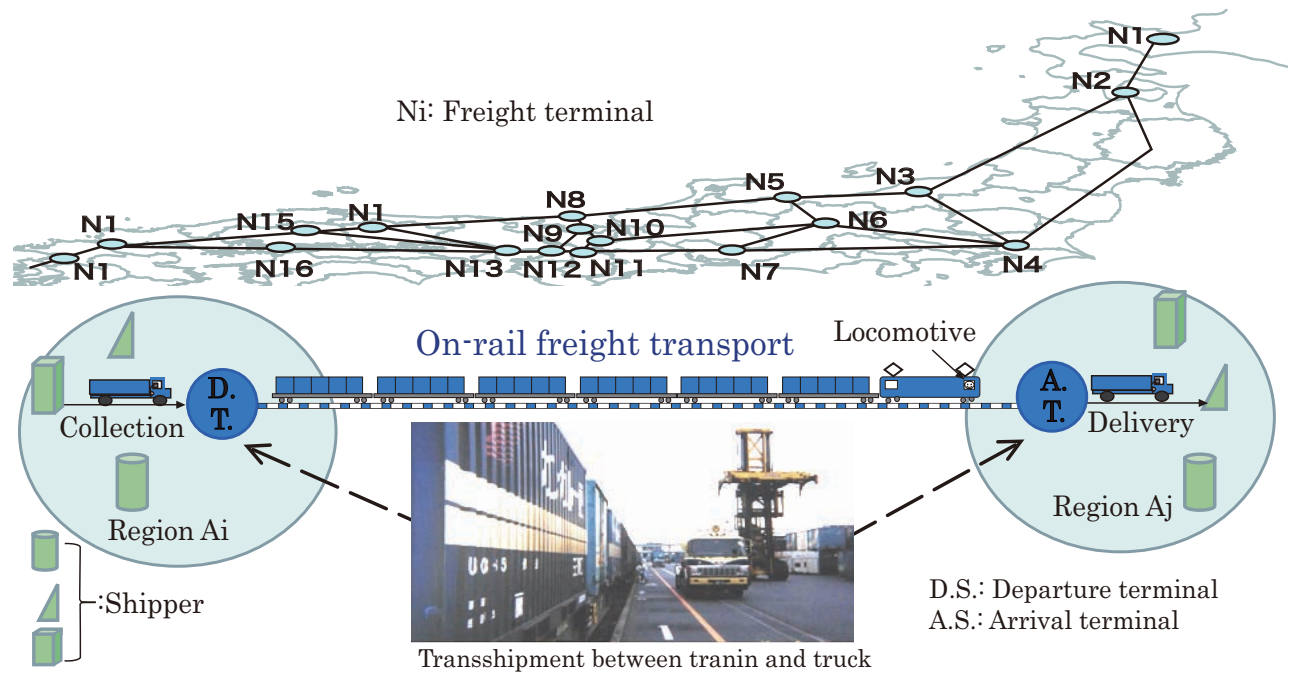

Fig. 1 Conceptual model of rail freight transport 


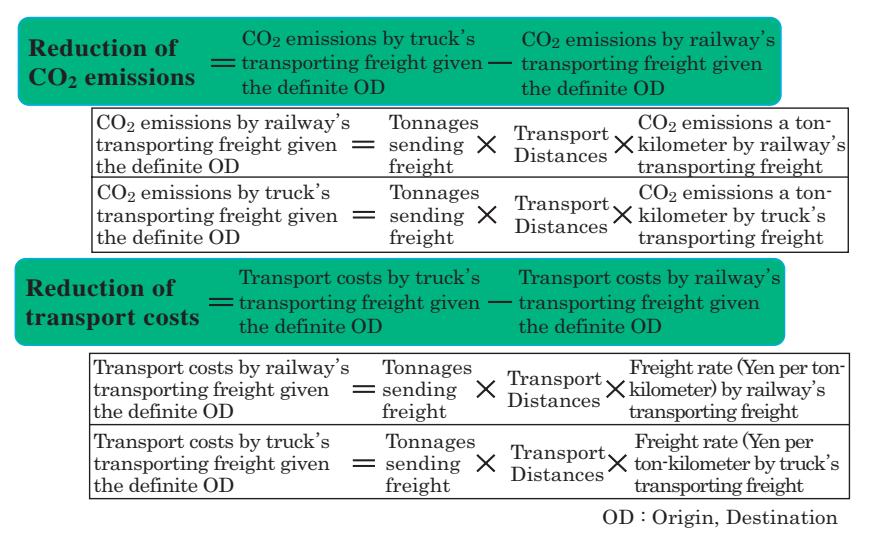

Fig. 2 Evaluation procedure for the effects of carrying goods by rail

delivery of containers.

4. Influential areas of freight terminals and their relationship with the target rail corridor

\subsection{Influential areas of freight stations}

Rail freight transport requires truck access for the collection of containers from shippers and their delivery to freight terminals and recipients. It is a freight terminal that allows a region to benefit from rail freight services. Part of the area served by the terminal is called the terminal's "influential area". Generally, the volume of freight handled at a terminal depends heavily on the distance from the terminal to shippers' premises. Therefore, the influential area of a freight terminal can be determined by examining the distance and distribution of shippers visà-vis the terminal, weighted by their shipment volumes.

Understanding the influential area of freight terminals is meaningful in at least two ways. Firstly, we can identify the geographical coverage of the shipped freight handled at the terminal. Secondly, it reveals the volume of surface freight transported by road within the influential area.

Figure 3 illustrates an example of the regional average of the influential areas of freight terminals in terms of the departure freight shipped by manufacturers. Some variations between regions aside, the diagram confirms the general trend towards lower freight flows as distances from the terminal increase. Nonetheless, in some regions the influential area extends as far as 50 kilometers from the terminal.

For example, in region A9, $80 \%$ of the entire freight is shipped within 10 kilometers of terminals; however, approximately $10 \%$ is from areas located further than $50 \mathrm{ki}$ lometers from terminals. In regions $\mathrm{A} 3, \mathrm{~A} 5$ and $\mathrm{A} 1,30$ to $40 \%$ of all the freight shipped originates from within 10 kilometers of the terminal, while 20 to $30 \%$ is from more distant areas.

Influential areas for freight arrivals are confirmed as similar to those for departing convoys. Thus, the influential area of a freight terminal is considered to extend farther than 50 kilometers from the freight terminal.

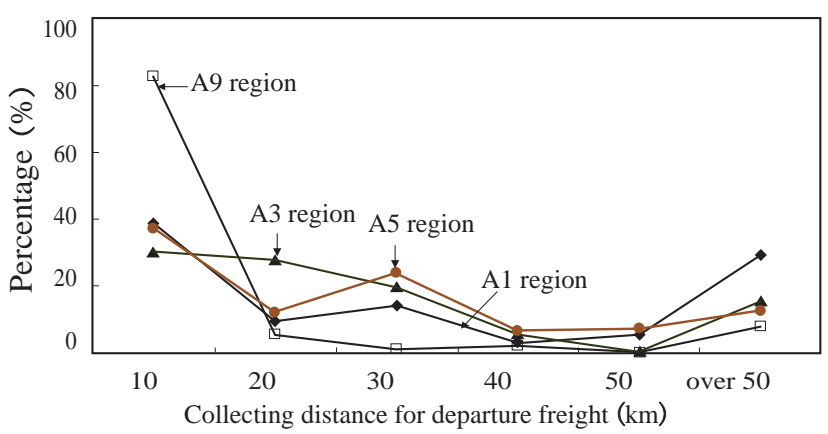

Fig. 3 Regional average distributions of the influential areas of freight terminals for departure freight shipped by manufacturers

\subsection{Relationships between the target rail corridor and freight terminals}

Analysis of rail freight transport shows that corridor N12-N13, as depicted in Fig. 1, is one of the most important corridors in the rail network. Nationwide, over 53\% of the total freight volumes pass along the corridor, and the proportion exceeds $60 \%$ for metal products, chemical products and miscellaneous products.

Using corridor N12-N13 as an illustrative example for the relationship between the target corridor and freight terminals, the proportion of freight dispatched from a certain region passing along the corridor indicates the strength of the relationship between the regions where the terminals are located and the corridor. For example, $87.5 \%$ of total freight dispatched from terminal N4 in region $\mathrm{A} 3,81.1 \%$ from $\mathrm{N} 16$ in $\mathrm{A} 7$, and $75.6 \%$ from $\mathrm{N} 18$ in A9 passes through the corridor, implying a strong relationship between these regions and the corridor.

The situation of freight transport passing along the corridor from every region has thus been elucidated.

\section{Criteria for judging the advantages of rail freight in terms of transport cost}

It is clear that benefits are obtainable not by trains transporting all freight, but that the extent to which rail freight transport is beneficial should be determined.

On the premise that shippers choose the cheapest transport mode, Fig. 4 shows that the criteria against which the cost advantages of rail freight transport are judged, using the analysis model of the logistics costs reductions induced by rail freight and the transport cost model for railway containers [1].

For example, the freight transport cost of railway containers will be cheaper than 10-ton trucks when the transport distance is greater than 350 kilometers. Naturally, the advantages of each transport mode cannot be judged exclusively in terms of cost, but there do exist freight convoys that may potentially be shifted to rail where the cost of transport by rail is cheaper than by road. 


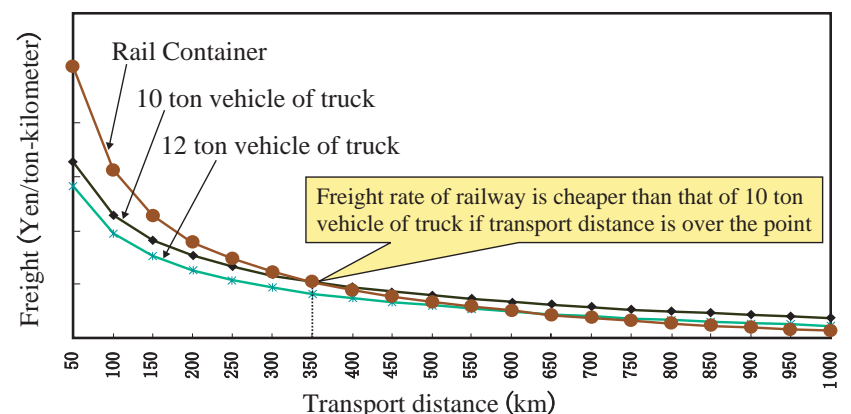

Fig. 4 Criteria for judging to what extent rail freight transport is advantageous

\section{Effects of freight transport on the target rail corridor}

\subsection{Conceptualizing the effect of rail freight}

As stated previously, rail freight transport is evaluated based on the current situation of and restrictions on freight transport along corridors. Social and economic benefits include the present effects of the carriage of freight by rail and the potential effect that may be induced by shifting freight to rail.

(1) Current effect

The current effect denotes the level by which logistics costs and $\mathrm{CO}_{2}$ emissions are reduced due to goods currently being transported by rail.

First, the freight transported on the target corridor is ascertained from the current inter-regional freight transport data, and $\mathrm{CO}_{2}$ emissions and logistics costs are estimated based on the routing of rail freight. Next, both amounts are estimated assuming that said freight is transported by road. The comparison of the two gives us the evaluated current effects of rail freight transport on the target corridor.

(2) Potential effect

A potential effect assumes there will be a reduction in logistics costs and $\mathrm{CO}_{2}$ emissions if freight currently transported by road is shifted to rail.

First, based on the influential area of freight terminals described previously, the route of surface freight transported by road within the influential area is determined. Next, based on freight transport data, the interregional surface freight able to be transported along the corridor is determined, with due allowance made for the target rail corridor's transport capacity.

Of course, the important task for rail freight operators is to provide capacity that meets shippers' demand. This should be discussed further as an issue affecting the rail network as a whole.

Shipper benefits are judged to be the advantages for them stated previously [1]. Surface freight shipments for which rail can achieve cost reductions are considered as freight that can be shifted from road to rail.

Comparison of $\mathrm{CO}_{2}$ emissions levels and logistics costs between rail and road will reveal the potential social and economic effects which can be induced on the target corridor.

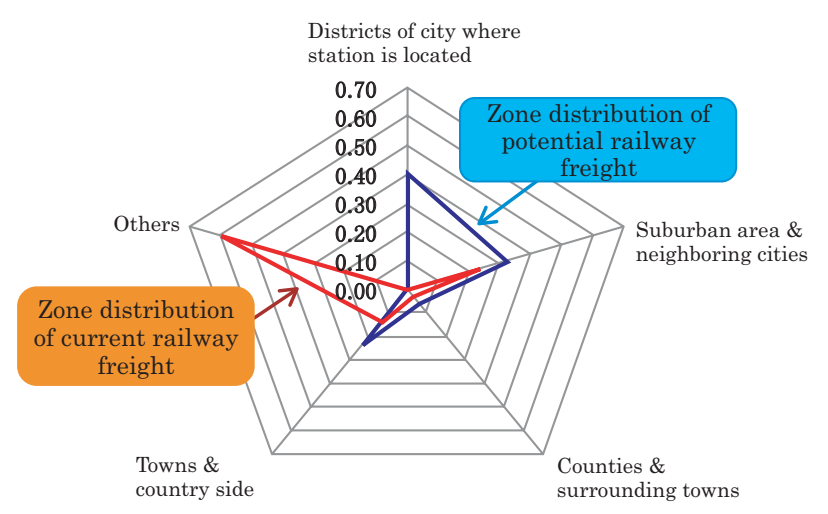

Fig. 5 Distribution by zone of freight collection at one terminal in case study

\subsection{Case study}

Corridor N12-N13 in Fig. 1 is used for the case study to evaluate the effectiveness of rail freight transport.

First, the distribution of inter-regional surface freight within the influential area of freight terminals along the target corridor was determined. The influential area comprises the districts of the city where the terminal is located, the suburban area and neighboring cities, counties and surrounding towns, and towns and countryside. "Others" includes adjacent areas and unidentified locations.

An example terminal has been chosen to illustrate. Figure 5 shows the distribution of dispatched freight shipped by manufacturers within the influential area of a freight terminal. The red line in the figure indicates the current distribution of the freight collected and brought to the terminal, while the blue line denotes the potential range within which freight can be collected but where it is currently transported by road. The figure confirms the concentration of freight in "suburban area and neighboring cities," "towns and countryside" and especially in "others." The reason for this trend should be discussed further; however, one point may be that this terminal handles freight shipped by manufacturers located in adjacent areas. On the other hand, the figure indicates that the majority of the potential freight is located in "districts of city", "suburban area and neighboring cities" and "towns and countryside".

Next, the distribution of collected freight for the corridor N12-N13 was determined from the freight distribution for each freight terminal on the corridor. This was done first by selecting the freight dispatched within the influential area of the freight terminal which was able to be transported on corridor N12-N13, and then judging whether it would be more advantageous to transport such freight by rail as opposed to by road.

Figure 6 shows the distribution of freight collected and brought to the terminal for corridor N12-N13 after judging whether the freight was located within the influential area. The figure indicates that the majority of the potential freight shipped by manufacturers within the influential area is located in "suburban area and neighboring cities", "towns and countryside" and "districts of the city." 


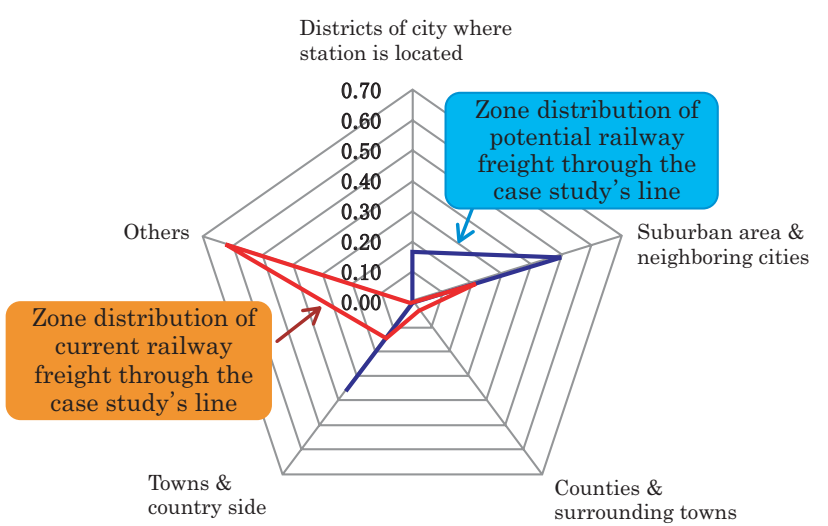

Fig. 6 Distribution by zone of freight collection along the target railway corridor at one terminal in case study

The same procedure was conducted for all freight terminals nationwide to discover the current and potential volume of rail freight on the target corridor.

The social and economic effects of transporting freight on corridor N12-N13 on the country as whole and on each region are evaluated as follows:

The current effect is 12.9 billion yen in cost reductions and 780 thousand tons in $\mathrm{CO}_{2}$ emissions reductions. The modal shift of freight transport from road to rail on corridor N12-N13 would save 49.3 billion yen in costs and 3.96 million tons of $\mathrm{CO}_{2}$ emissions.

Figure 7 shows the reduction in $\mathrm{CO}_{2}$ emissions which could potentially be achieved in each region via modal shift. The Kanto, Kinki and Tokai regions will potentially benefit most from rail freight transport.

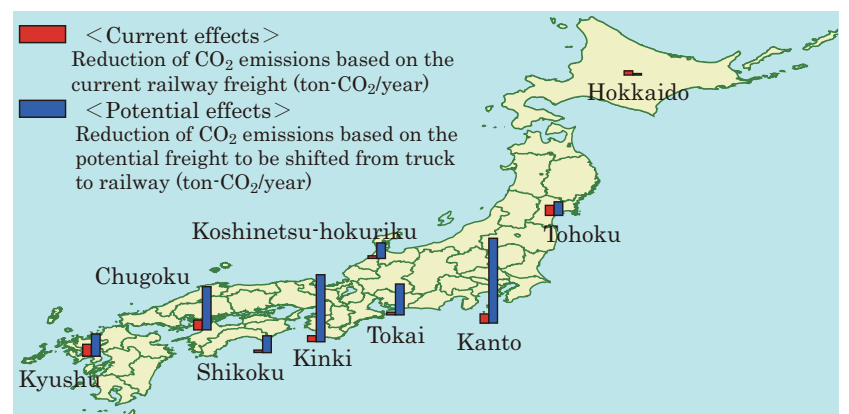

Fig. 7 Effects of carrying freight by rail along the line examined by the case study

\section{Conclusion}

This study discussed an evaluation method for rail freight transport from the perspective of reducing logistics costs and environmental load.

The paper first analyzed the current situation with regard to domestic inter-regional surface freight and the position of rail freight transport in this market. An evaluation method for rail freight was then proposed, and the influential area of freight terminals and criteria for judging rail freight were discussed. Based on the foregoing, current rail freight volumes and the potential freight volumes that could be shifted from road to rail are determined via a case study on the target rail corridor. Finally, the reduction in logistics costs and $\mathrm{CO}_{2}$ emissions on the target rail corridor were calculated. This method is expected to be an important tool in quantitatively evaluating the benefits of rail freight transport.

Further studies may include the application of this method to the existing rail freight transport system, and an elaboration of the methodology.

\section{References}

[1] LI, G. and Muto, M., "Analysis of the effectiveness of logistics costs reduction by using rail for inter-regional surface freight transport," RTRI Report, Vol. 22 , No. 6, pp. 41-46, 2008 (in Japanese).

[2] Ministry of Land, Infrastructure, Transport and Tourism, "Regional Freight Flow Survey," http:// www.mlit.go.jp/

[3] LI, G., "Intermodal Freight Transport," Railway Research Review, Vol. 66, No. 3, pp. 30-33, 2009 (in Japanese).

[4] Ministry of Land, Infrastructure, Transport and Tourism, "National Commodity Flow Survey," http:// www.mlit.go.jp/

[5] LI, G., "Modal Shift in Freight Transport," Railway Research Review, Vol. 66, No. 12, pp. 6-9, 2009 (in Japanese).

[6] LI, G., Tamura, K. and Okuda, D., "Analysis of potential freight volumes for railway container traffic based on the current situation in inter-regional surface transport," Journal of Railway Mechanics, JSCE, Vol. 13, pp. 104-109, 2009 (in Japanese). 